\title{
Understanding the Magical Property of the Desharis, Bejunis (Witch Doctors) of the Kandhs of South Orissa
}

\author{
Gokulananda Patro
}

\begin{abstract}
Deshari, Bejuni, Shamanins are known as indigenous physicians or Vaidyas among the Kandhas of south Orissa. The Deshari is well acquainted with the medical effect of the roots and herbs required for curing of the diseases using charms and spells. Bejunis are experts for the treatment of mental patients. Through magical spells and charms (known as white Magic), she takes up the cases of mental illness. The services of Shamanins are requires for harming an enemy by mantras and tantras.They are expert in Black Magic. Kandhs are experts or specialists in treatment of drowned, night goblin, labour pain and pain in mother's breast and pulta-bagha. This particular magical property enabled them to transform themselves into tigers and in this shape to attack human beings and their cattle ${ }^{1}$. John Campbell, a top ranking ICS officer witnessed such cases of Pulta-bagha in his own eyes. Their magical properties are amazing and tremendous. But they had no written books on this magical property. It goes from mind to mind, mouth to mouth and generation to generation. The charms, spells, magic-lores, magic cords, folk method of treatment and folk medicines are the traditional heritage of these people. If we will not collect, document or preserve in digital form, this valuable wealth of the centuries will disappear from the society very soon. An humble attempt has been made in this paper to present a vivid account of the role of Desharis, Bejuni, Shamanins and their magical property for the treatment of the diseases.
\end{abstract}

Keywords: Desharis, Bejunis, Shamanin, Ojhas, Guniyas, Sakhas, Maits, Boyas, pulta-bagha, Panji, Ahiraj, Pat-Bejuni, Dharani-Penu

\section{INTRODUCTION}

The Kandhs are one of the oldest hill tribes of South Odisha. They are very conservative, ignorant and superstitious. They believe in supernatural powers of village doctors like Deshari, Bejuni, Shamanin, Witches and Sorcerers for the cure of diseases. Their religious beliefs are different from rest of the people of Odisha. They had different nomenclatures for different Goddess and Spirits. All their Gods and Goddesses are propitiated by the Desharis with the sacrifices of animals, birds and even human beings.

Manuscript received on July 20, 2021.

Revised Manuscript received on July 30, 2021.

Manuscript published on July 30, 2021.

* Correspondence Author

Dr.Gokulananda Patra*, Head, Department of History, K.M. Science College, Narendrapur, Ganjam (Odisha).

(C) The Authors. Published by Blue Eyes Intelligence Engineering and Sciences Publication (BEIESP). This is an open access article under the CC BY-NC-ND license (http://creativecommons.org/licenses/by-nc-nd/4.0/)
They were only community in Odisha who practised human sacrifices to satisfy their Goddesses during $19^{\text {th }}$ century $^{2}$. They believed that all diseases are caused by the mischief of some evil spirits and the displeasure their presiding deity. Therefore, they engage Deshari, Bejunis, Shamanins for the cure of diseases and propitiation of the ditties.

Deshari, Bejuni, Shamanins are known as indigenous physicians or Vaidyas among the Kandhs of south Orissa. The Deshari is well acquainted with the medical effect of the roots and herbs required for curing of the diseases using charms and spells. The Sorcerers or witch doctors are also known as Ojhas, Guniyas, Sakhas, Maits, Boyas in different tribal areas of India ${ }^{3}$. Different sources of different tribal groups are specialists in different treatment as for example Sauras are expert in dealing with evil spirits. Kandhs are specialists in treatment of drowned, night goblin, labour and pulta-bagha.

\section{ROLE AND FUNCTIONS OF DESHARIS}

Deshari plays an important role in the diagnosis and treatment of disease. On the basis of certain symptoms or divination he diagnoses the disease. On the other hand, the Bejuni, who is a shamanin and who is also supposed to cure disease, traces out the deity behind the disease. In order to do this she performs necessary rites, gets into trance, and realizes hallucinatory revelation, sacrifices animal as per the demand of the deity or spirit. Thus, when the deshari diagnoses diseases with local herbs and roots perforated with divination, the Bejuni diagnoses the disease only through necessary rituals and divinations. ${ }^{4}$ The post of Deshari is hereditary but if his son is not competent, any man who develops the art becomes Deshari. There are one or two Desharis in all the big villages of kandh hinterland of south Odisha. As a folk doctor of the village, he is highly esteemed and given higher status in the society.

The Kandhs are firm believers in magic and sorcery. Certain painful experiences in their day-to-day life like diseases, deaths and accidents led them to believe in the existence of an invisible spirit. It was believed that this spirit could be appeased by the chanting of some mantras and bearing of amulets and magic cords. This practice is called magic or sorcery. ${ }^{5}$

This was professed by one who claimed to possess the power to work marvels, not through the aid and counsel of the supernatural powers but by certain occult faculties and devices. Persons who professed it belonged to both the sexes. The man who did it best in the southern Odisha was called Deshari.

Published By:
Published By:

\& Sciences Publication

(c) Copyright: All rights reserved.

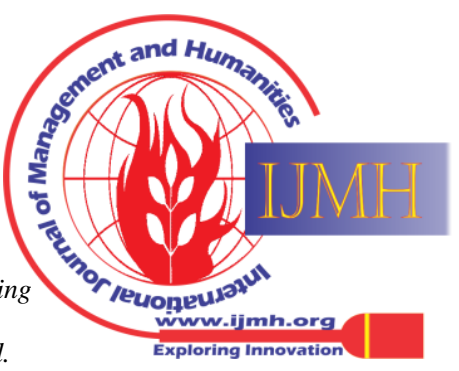


Deshari begin his practice as the result of a series of spiritual experiences with a Goddess who, having guided him into his profession remained there after his mentor and media tress with the Gods. He was respected by the tribe who regarded him as one specially chosen by a Goddess. He was also accredited with possessing supernatural powers and being a sorcerer. His functions were chiefly to counteract the harm of evil spirits as manifested by inauspicious omens and the various illnesses that plagued the inhabitants. ${ }^{\mathbf{6}}$

However, for the detection of such persons (witches?) several ordeals used to be performed. Sometimes the Deshari was called upon to examine the panji (palm leave manuscript) and name the person suspected to be the witch. The witch-doctor or Deshari was believed to have control over those ill-willed forces. The Deshari, who mostly uses herbal medicines, collected from the nearby forests, applies them in following manner for different diseases.

To stop bleeding, Latchiri-creeper is made paste and anointed over the wound. Immediately after the preliminary aid, paste of leaves of Drayakala plant or Luhatarchi plant is applied at the wound. For quick recovery from a fatal injury warm turmeric paste is also applied.

For any sort of burn injury, cow dung is applied immediately. Later on, the bark of Manda tree is soaked in water for a day and then grinds to prepare a sort of paste which is applied on burn bruises for healing up.

In order to lighten the pain of a sprain, castor-oil is boiled with turmeric paste and applied three to four times a day over the sprain. Sometimes a paste prepared out of Bishalyakarani is applied over the sprain after heating it up. And upon this sort of balm, a tender banana leaf is covered and tied up with a piece of cloth for a day or two in case of bone fracture. $^{7}$

The southern part of Odisha is a land of high hills and dense forests. It is infested with gigantic snakes like Ahiraj (King of snakes), Pythons, Sankhachuda and poisonous snakes like Cobra, Tampa, Chiti and Boda. ${ }^{\mathbf{2}}$ When the people are caught by snake bite they never go to any hospital or doctors. They themselves are petty doctors. Roots of patala garuda and Fapana plant are grind together and applied over the wound caused by either a snake or a poisonous insect. As an antidote to the poison, caused by venomous snakes, roots of a creeper, locally called gadda, is grinded and orally administered.

For healing up of fracture, Hadsikula creeper is also used by the Kandhs. A tender portion of the creeper is collected and then it is grind to a thick paste which is evenly applied over the fractured bones, which is then tightly fastened by placing two pieces of split up bamboo on either side of it.In case of vomiting, Bhusanda (roots of Patal Garuda) is grind up and then orally taken, for cure of diarrhea pulverized root of Kumdi plant is taken along with water.Roots of Anahinga plant, Bachha or Daja plant and arrow-root (Badhra) are grind together and diluted with Mahua liquor (Irpi Kalu) in order to prepare a lotion which is anointed over the entire to get rid of fever.Seeds of Tralu tree are collected. The skins of the seed are taken out. Root of Ketkaya plant is mixed with entire substance is diluted with water and used twice a day to get rid of cold.For cure of indigestion, the roots of Sarumaricha plant and roots of Bhusanda (Patal Garuda) plant are grind together and taken with water three to four times a day.Roots of Kumdi plant and roots of Bhusana plants are pulverized together and then mixed with water. It is taken three to four times a day. It is a

curative for any sort of gastro-internal disease. ${ }^{\mathbf{9}}$ Kandh's open-air movement, less liking for confinement in houses and frequent movement in hills and forests tend him to pick up basic knowledge of certain medicinal herbs and roots which either he gathers or brings immediately for treatment. Only when his personal knowledge falls he approaches the practitioner. In almost all the big villages there are one or two Deshari who are consulted even in odd hours.

The practitioner verifies certain symptoms after checking the palpitation of the right wrist of the female or left wrist of the mole and accordingly diagnoses the disease. Eyes and tongues are not checked only stomach is pressed after due checking the practitioner diagnoses the disease and prescribes the medicine.

The practitioner is the custodian of indigenous herbs and roots. He, after due checking, takes out appropriate herbs or ready-made medicine, utters some magical spells solemnly and puffs on the medicine as well-as on the patient three to four times. It is believed that the Ghungi Penu a goddess is worshipped by the Deshari and appeased with adequate sacrifices so as to acquire the knowledge of the art.

Usually Deshari does not demand any fee for the treatment. The patient pays only nominal fees and when cured, he pays what he likes as gift either in kind or cash. The post is also not hereditary. If the son likes, he learns some spells and charms to appease the Penu in connection with different treatment. As an indigenous physician, Dashari commandas great respect in the tribal villages and given higher status in the society. ${ }^{10}$

\section{FUNCTIONS OF BEJUNIS}

Bejunis are expert in White Magic the treatment of mental patients through magic is practiced by Bejunis. Through white magic she takes up treatment of mental illness. People also believe that through magical diagnosis the diseases can be cured. The Pat-Bejuni tests the external symptoms of the patient. From the very look of the patient, she can guess the type of disease which the patient is suffering from, and then determines the main causes of sufferings. Afterwards she resorts to the procedure of divination and invokes charms to identify the appropriate spirits. The Bejuni or the Shamanin is another kind of tribal physician who treats patient of mental illness through white magic. In the performance of rites, when a Bejuni gained proficiency after rigorous training becomes Pat-Bejuni.

The Pat-Bejuni, along with her assistants, starts supplicating sundried rice balls separately in winnowing fans with magical spells and charms so as to trace out the concerned spirit which has done the harm. In case, the spirit remains unidentified even after long recitation, Pat-Bejuni jumps off and starts dancing. Immediately the disciples follow her. While dancing she is possessed by the spirit. It is believed that the real spirit who is causing harm gets into her body. She ultimately gets into trance and starts talking to the spirit on behalf of the patient in that state of trance. She vows to placate and appease the spirit with whatever sacrifices the spirit desired to have. After that she gets back her senses and prescribes for ritualistic articles to be offered to the spirit.

Blue Eyes Intelligence Engineering \& Sciences Publication (C) Copyright: All rights reserved. 
Accordingly rites are performed and sacrifices are given. The Pat-Bejuni tests the external symptoms of the patient. From the very look of the patient, she can guess the type of disease which the patient is suffering from, and then determines the main causes of sufferings. Afterwards she resorts to the procedure of divination and invokes charms to identify the appropriate spirits.If, even after this, the patient is not cured, a more efficient Pat-Bejuni is consulted, who performs rites more elaborately and offers more sacrifices. And if after this the patient is not cured, the matter is left to be decided by the Earth-Goddess known as Dharani-Penu.

\section{ROLE OF THE SHAMANINS}

The Shamanin is the assistant of Dasharis and Bejunis. She assisted in awarding- off the evil spirits and deities as well as to appease them with appropriate rites and sacrifices. The symptoms of the disease are ascertained first by the Shamanin. For harming an enemy also the services of a Shamanin is sought. The type of occultism which she uses for infliction misfortune and harm on a target person is called Peshini. Such an art may be termed as contagious or black magic. It is not public but secretly practiced lest the party may be bewitched by more experienced practitioner.

However, only when medical therapy fails, the people take recourse to magical therapy, that is, they approach the Shamanin to take up the treatment.

The symptoms of the disease are ascertained first by the Shamanin. Shamanins are organized on the basis of their respective tutelary spirits, whom they worship. In each group the Pat-Bejuni or the chief Shamanin takes the lead in divinations or in the performance of rites, who supposed to have gained proficiency in the art after rigorous training. Though there are male Shamanins, their number is much less. When they act, they adorn themselves with ladies garments. ${ }^{11}$

\section{CONCLUSION}

The above discussion infers us to believe that the magical properties of the village doctors of the Kandh hinterland of South Odisha are very valuable. The Deshari, Bejuni, Shamanin play an vital role in diagnosing the diseases of the patient and enjoy high respect in the Kandhs society. Although they are illiterate and has no sound knowledge on literature they use spells, mantras, charms, magical cords, magical lore's and folk method of medicine to cure the different kind of diseases by chanting. But these are not available in the form of text or literature. These are transmitted from father to son, Guru to shisya, mouth to mouth and generation to generation. Therefore, steps maybe taken to collect and document this indigenous knowledge system of Kandhs in digital format. Otherwise, the magical property of the Kandhs will be disappeared from the society.

\section{REFERENCES}

1. H.H.Risely, The Tribes and Castes of Bengal, Vol 1, p 498 *John Campbell, A personal Narrative of Thirteen years services amongst the Wild Tribes of Khondisatan for the suppression of Human sacrifices, London, 1864, P.44

2. Selection from the records of the Government of India, Vol V, History of Rise and Progress of the Operations for the Suppression of Human Sacrifice, Female Infanticide in Hill Tracts of Orissa, 1866- 54, Calcutta, 1854, p 89

3. S.S.Gupta, Folklore and Folk life in India Calcutta, 1959, p.151.

4. N.R.Patnaik, Studies and Superstitious belief, Myths,

Published By:

Witchcrafts, Sorcery and Sacrifice of the $19^{\text {th }}$ century Orissa, in Orissa Historical Research Journal, Vol XXXIII,nos3-4,pp129.

5. L.P.Vidyathi and B.K.Rai, The Tribal Culture of India, Delhi. 1977, p244.

6. Watts Neville A, the Half Clad Tribal of Eastern India, Bombay, 1970, p363.

7. N.Patnaik and P.S.Das Patnaik, The Kandhs of Orissa, Bhubaneshwar, 1982, p177.

8. Bhagabana Sahu,Folk Life and Culture of Odisha,New Delhi,2015,p268.

9. Collected information from the Desaris of Ghumsar by the author in the field study undertaken in the tribal hinterlands.

10. Revealed from the field study conducted by author in the Belghar region of Orissa

11. N.Patnaik and P.S.Das Patnaik, op.cit.

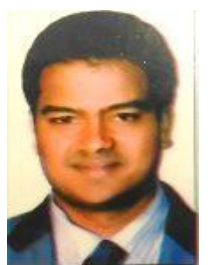

Dr.Gokulananda Patra, (born in 1984) obtained B.A in 2004 securing first class first position and M.A. in History in 2006 with first class first position. He was awarded Ph.D. Degree in History in 2016. He is the Life Member of Orissa History Congress, South India History Congress, Indian History Congress and South Odisha History Society. He has contributed a number of research papers to different journals of National and chapters in books. His book History of Communication and Transport in Odisha is highly appreciated; He is serving as Head, Department of History, K.M. Science College, Narendrapur, Ganjam (Odisha). 